\title{
Effect of Family Stress on Life Satisfaction Among Female Workers During the COVID-19 Epidemic in China: Exploring the Roles of Anxiety Symptoms and Age
}

\section{Songli Mei}

Jilin University School of Public Health

\section{Tongshuang Yuan}

Jilin University School of Public Health

\section{Leilei Liang}

Jilin University School of Public Health

Hui Ren

Jilin University School of Public Health

\section{Yueyang Hu}

Jilin University School of Public Health

\section{Zeying Qin}

Jilin University School of Public Health

Junsong Fei

Jilin University School of Public Health

\section{Ruilin Cao}

Jilin University School of Public Health

\section{Chuanen Li}

Jilin University School of Public Health

Yuanchao Hu ( $\nabla$ Hu_yuanchao@sohu.com )

Jilin University School of Public Health

\section{Research article}

Keywords: COVID-19, Life satisfaction, Family stress, Female workers, Anxiety symptoms

Posted Date: March 31st, 2021

DOl: https://doi.org/10.21203/rs.3.rs-368793/v1

License: (9) This work is licensed under a Creative Commons Attribution 4.0 International License. 
Version of Record: A version of this preprint was published at Journal of Health Psychology on October 18th, 2021. See the published version at https://doi.org/10.1177/13591053211044824. 


\section{Abstract}

Background: High level of life satisfaction (LS) means an individual's positive evaluation of life, bringing a happy and upward attitude towards life, which is beneficial to physical and mental health. However, The LS of a particular group such as female workers has not yet been fully explored. The present study aimed to investigate the level of LS among female workers after the resumption of work during the Coronavirus Disease 2019 (COVID-19) epidemic in Jilin Province, China, and to further explore the potential mediating and moderating roles in the association between family stress and LS.

Methods: A cross-sectional survey was conducted from July to August in 2020. A self-reported questionnaire including the background information, family stress, anxiety symptoms, and LS was used to collect information in this research. A total of 10,175 female workers completed questionnaires.

Results: The results showed the LS score was $20.73 \pm 7.08$. The family stress was negatively related to LS, and anxiety symptoms could partially mediate the effect of family stress on LS. Additionally, age moderated the relationship between family stress and LS, as well as the relationship between anxiety symptoms and LS.

Conclusion: Our results indicated that the LS of female workers has declined due to the impact of the epidemic, and family stress impacted LS via anxiety symptoms. The effect of family stress on LS decreased as age increased. Overall, Interventions and preventions aiming to improve LS should thoroughly consider targeting these aspects and young female workers should be given special attention.

\section{Background}

In December 2019, the Coronavirus Disease 2019 was initially reported, and it quickly spread to 24 countries across the national and global [1]. The COVID-19 epidemic has been identified as a global major public health event, posing a huge threat to people's physical and mental health [2]. At present, the epidemic situation in China has been effectively controlled. However, the situation remains vigilant due to the increasing number of imported cases. The resumption of work and production also increase the risk of the rebound of the epidemic by increasing the population mobility and population density.

A number of researches has demonstrated that the stress associated with COVID-19 increased significantly [3-5], and a nationwide survey which conducted on the general population of China during the instable period of the COVID-19 epidemic reported that 35\% suffered from psychological distress[6]. Additionally, the research results show that women suffered higher levels of stress of the COVID-19 epidemic[7]. On an individual level, the infection could trigger stress through several aspects, such as fear of oneself and family members being infected, reduced family income, increased burden and time spent on taking care of children, and strained family relationships. As for female workers, due to special family and social roles, stress arose from family become one of the major stressors. All these events and situations will cause women to face greater challenges and bear greater stress from family[8]. There is 
enough evidence to demonstrate COVID-19 was a life-threatening public health emergency, and such stressful event can directly affect individual's LS $[9,10]$. When an emergency occurs, women are more vulnerable than men and adopt fewer effective coping strategies. On the other hand, women show obvious sensitivity to loss and stress, so they are more likely to produce negative emotions such as depression and anxiety [11]. In this context, women are more susceptible to the disastrous events compare to men, and they show more dissatisfaction with life [12].

LS is the comprehensive judgment and evaluation of the current life situation based on one's own standards [13], which is an important part of subjective well-being. It is a process that can bring out positive influence, self-dedication and make lives more meaningful [14]. The low level of LS implies more occupational injury at work which increases the social burden and affects personal health [15]. However, previous research on LS mainly focused on college students, the elderly and people with specific diseases [16]. There is a lack of research investigating the LS of female workers after the outbreak of COVID-19. Therefore, under the normalization of COVID-19 epidemic, this study explored the impact of family stress on LS of female workers and investigated the underlying mediating and moderating mechanisms, which can provide a basis for improving LS and their mental health.

Previous research has shown that public health events not only bring huge casualties, property losses, and severe psychological trauma to those who have experienced it, but also has impacts on mental health among the public [17-19]. For example, the novel influenza A (H1N1) epidemic in 2009 and the Middle East Respiratory Syndrome (MERS) epidemic in 2012 lead to serious psychological problems such as depression, anxiety [20], post-traumatic stress disorder [11], etc. Anxiety, as a widespread and serious psychological problem, may affect people's daily life in various ways, including poor interpersonal relationships, poor quality of life, and decreased LS $[21,22]$. It has demonstrated that anxiety symptom was negatively correlated with LS [23-26]. Moreover, studies have shown that accumulated stress can trigger a series of psychosomatic reactions, aggravates physical fatigue and induce negative emotions, leading to anxiety, depression and even suicidal ideation [27-30].As a result, we proposed hypothesis 1 that anxiety symptoms mediate the relationship between family stress and women's LS.

Although family stress may have an indirect impact on LS via anxiety symptoms, not all people with more severe anxiety symptoms or higher family stress level will have lower level of LS. Accordingly, it is necessary to explore the influential factors that could strengthen or weaken the link among family stress, anxiety symptoms and LS. The previous researcher has found that age can influence the association between family stress and LS [31]. As for female workers with different ages, taking into account the different levels of family stress and the different sensitivities toward family stress, age may be a moderator of these relationships. In the past researches, some studies have concluded that age is not only closely related to quality of life, but also an important factor affecting anxiety symptoms [32, 33]. And it has reported during the SARS outbreak that mental health is closely associated with age[7]. Hence, it is reasonable to assume that the direct and indirect impact of family stress on LS may be moderated by age. Based on the above background information, we proposed hypothesis 2 that age would moderate the direct and indirect association between family stress and LS. 


\section{Methods}

\section{Participants and procedures}

We contacted the representatives of employing units via letters for invitation and follow-up calls with strong supports from Female Workers' Committee of Jilin Federation of Trade Unions. All employing units including businesses, individual economic organizations, people-run non-enterprise units and labor organizations in Yanbian Korean Autonomous Prefecture, Jilin province, China were invited to participate in the survey. Approximately $50 \%$ of the employing units gave positive responses and agreed to participate in the study. Additionally, we conducted targeted recruitment in regions with insufficient sample to ensure the sample was representative. We sent questionnaires to representatives of each employing unit through 'Questionnaire Star' electronic questionnaire system, which is an application designed to create and distribute electronic questionnaires via Wechat or web page. Then representatives shared questionnaires with their female workers who answered them on smartphones or computers in working groups. All responses were saved on the 'Questionnaire Star' servers for us to download and analyze later. The cross-sectional study was conducted between July and August of 2020, during the time when epidemic situation was stable in China and people have return to work. Participants completed the online survey including sociodemographic variables like age, education level, marital status, annual income, and family stress, anxiety symptoms and LS. The study protocol was approved by Medical Ethics Committee of Jilin University. The first page of the questionnaire is an informed consent which shows to participants. Participants are fully aware of the study procedures and choose to participate in the study voluntarily. All data collected was confidential and anonymous to fully protect the privacies of the participants. Inclusion criteria: Age ranges between 18 and 60 years old. The exclusion criteria included flowing: missing response of research variables; the response time less than 2 minutes; different answers to duplicate items; with diagnosed psychological disorders.

A total of 10,900 female workers completed the survey and 10175 valid questionnaires were collected, yielding an effective response rate of $93.35 \%$. The average age of the participants was 40.39 (standard deviation=8.81).

\section{Measures}

\section{Satisfaction with life}

LS was measured by the 5-item Satisfaction with Life Scale (SWLS) developed by Diener [13] with a 7point Likert scale, which is probably the most well-used scale in scientific studies on LS [15]. Each item with seven options varying from 1 (strongly disagree) to 7 (strongly agree), with higher scores indicating higher satisfaction with life. Vassar et al. reported an internal consistency of 0.78 [34] and in this study Cronbach's a coefficient of the SWLS was 0.91.

\section{Family stress}


Family stress Scale was previously employed in Chinese women [35,36], including 5 items of relationship and conflicts with family members, household workload, economic burden, trouble with care giving, and spending too much time and energy on taking care of family members. Similarly, each item was also responded with a 4-point Likert scale, from 1 (strongly disagree) to 4 (strongly agree). The total score ranges from 5 to 20 constructed by 5 items was consequently calculated, with higher scores indicating higher family stress. The Cronbach's a coefficient of the Family stress Scale in this study was 0.87 .

\section{Generalized anxiety disorder}

The 7-item Generalized Anxiety Disorder Scale (GAD-7) was utilized to assess the anxiety symptoms and it validated in both the primary care setting and the general population [37, 38]. The GAD-7 has been found to have great psychometric properties and is short and easy to administer [38]. The GAD-7 has demonstrated adequate validity, good clinical utility and reliability, and generally strong psychometric properties in both primary care settings and the general population. The item on the questionnaire was rated on a 4-point Likert scale ranging from 0 to 3 . The high total score means severe anxiety symptoms. The Cronbach alpha in this study for this Scale was 0.87 .

\section{Data analyses}

All analyses were conducted using the SPSS version 24.0. In this study, descriptive statistics (numbers and percentages) were used to present social demographic characteristics. The score of LS were expressed as mean and standard deviation. Kolmogorov-Smirnov test were used to test the normality distribution of the LS scores. The independent samples $t$-test or one -way ANOVA was used to compare the average score in different groups. A two tailed $P$-value smaller than 0.05 indicated the presence of statistical significance. Pearson's correlation analysis was used to test correlation among age, family stress, anxiety symptoms, and LS. Additionally, we used multiple liner regression analysis and SPSS PROCESS macro to test the mediating role of anxiety symptoms and moderating role of age. Notably, this method produced $95 \%$ bias-corrected confidence interval for these effects from 5000 resamples of the data. If confidence intervals do not contain zero, the effects are considered significant [39]. Before testing the mediation and moderated mediation model, all variables were standardized.

\section{Results}

\section{Social demographic of the participants $(N=10175)$}

The social demographic characteristics of 10175 female workers and the distributions of LS were presented in Table 1. More than half of (60.7\%) women aged below 44 , and $39.3 \%$ women aged between 45 and 59 . As for marital status, the majority of participants (79.9\%) were married, follow by unmarried (12.2\%). 49.9\% women had an educational degree below undergraduate, and over half of the participants $(61.9 \%)$ with annual income between 30,001 and 60,000 . Most participants $(83 \%)$ were pregnant or had children. The average LS score of the women were 20.73 \pm 7.08 . Different distributions of demographics were found regarding LS scores for age, marital status, educational degree, annual income, occupation 
and pregnancy or childbirth. Women older than 45 years, receiving good education, and having higher annual income tended to have higher levels LS(P凶0.001). Regarding marital status, women who were married were higher than those of other groups $(P \otimes 0.001)$. Women have been pregnant or had children showed higher levels LS(P®0.001).More detailed information was shown in Table 1.

Table 1 Mean scores of LS according to social demographic characteristics $\quad(N=10175)$ 


\begin{tabular}{|c|c|c|c|c|}
\hline Variables & $\mathrm{N}(\%)$ & 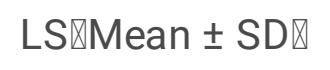 & $\mathrm{F} / \mathrm{t}$ & $P$ \\
\hline Age(years) & & & -8.545 & $\nabla 0.001$ \\
\hline$\leq 44$ & $6172(60.7)$ & $20.25 \pm 7.06$ & & \\
\hline $45-59$ & 4003(39.3) & $22.47 \pm 7.05$ & & \\
\hline Marital status & & & 80.594 & $\varangle 0.001$ \\
\hline Married & $8128(79.9)$ & $21.24 \pm 6.95$ & & \\
\hline Unmarried & $1239(12.2)$ & $19.33 \pm 7.09$ & & \\
\hline Divorced or widowed & $746(7.3)$ & $17.75 \pm 7.11$ & & \\
\hline other & $62(0.6)$ & $17.44 \pm 9.30$ & & \\
\hline Educational degree & & & 9.888 & $\nabla 0.001$ \\
\hline Below undergraduate & $5079(49.9)$ & $20.14 \pm 7.08$ & & \\
\hline Bachelor & 4913(48.3) & $21.04 \pm 7.06$ & & \\
\hline Master and above & 183(1.8) & $21.07 \pm 7.26$ & & \\
\hline Annual income & & & 87.988 & $\nabla 0.001$ \\
\hline$\leq 30,000$ yuan & 2694(26.5) & $19.11 \pm 7.13$ & & \\
\hline $30,001-60,000$ yuan & $6299(61.9)$ & $21.02 \pm 6.93$ & & \\
\hline $60,001-100,000$ yuan & 1104(10.8) & $22.77 \pm 6.95$ & & \\
\hline$\otimes 100,000$ yuan & $78(0.8)$ & $23.76 \pm 7.29$ & & \\
\hline Occupation & & & 18.597 & $\nabla 0.001$ \\
\hline Medical hygiene & 1990(19.6) & $20.24 \pm 7.06$ & & \\
\hline Education & $3485(34.3)$ & $21.48 \pm 6.798$ & & \\
\hline Financial industry & $289(2.8)$ & $20.08 \pm 7.08$ & & \\
\hline Electronic industry & $329(3.2)$ & $19.06 \pm 7.35$ & & \\
\hline other & $4082(40.1)$ & $20.45 \pm 7.24$ & & \\
\hline Pregnancy or childbirth & & & 5.783 & $\nabla 0.001$ \\
\hline Yes & $8444(83.0)$ & $20.91 \pm 7.04$ & & \\
\hline No & $1731(17.0)$ & $19.82 \pm 7.20$ & & \\
\hline
\end{tabular}




\section{Correlations among continuous variables}

Table 2 displayed the results of Pearson's correlation analysis. Age, stress, anxiety symptoms, and LS were significantly correlated with each other in the expected direction. And the results indicated that both family stress and anxiety symptoms had significant negatively correlation with LS.

Table 2 Correlations among family stress, anxiety symptoms and LS

\begin{tabular}{|lllll|}
\hline Variables & 1 & 2 & 3 & 4 \\
\hline 1.Age & 1 & & & \\
\hline 2.Family stress & $0.047^{\star \star}$ & 1 & & \\
\hline 3.Anxiety symptoms & -0.016 & $0.513^{\star \star}$ & 1 & \\
\hline 4.Life satisfaction & $0.082^{\star \star}$ & $-0.500^{\star \star}$ & $-0.374^{\star \star}$ & 1 \\
\hline
\end{tabular}

Note: ${ }^{*} P<0.05,{ }^{* \star} P<0.01$

\section{Testing for the Mediation Model}

Hypothesis 1 stated that anxiety symptoms will mediate the association between family stress and LS. The multiple liner regression analysis [40] was adopted to test the mediation effect. As presented in Table 3. The first step indicated that the regression of family stress on LS was significant $(B=-1.13, p<0.001)$, and the regression of family stress on anxiety symptoms was also significant in the second step ( $B$ $=0.74, p<0.001)$. The last step demonstrated that the regression of anxiety symptoms on LS was significant $(B=-0.24, p<0.001)$, and when the family stress and mediator (anxiety symptoms) were both included in the model as independents, the path coefficient of the family stress on LS remained significant $(B=-0.95, p<0.001)$.

Besides, the PROCESS macro (Model 4) was used and a bootstrap procedure conducted to examine the mediating effect. 5000 bootstrapping samples was generated from the original dataset $(N=10175)$ via random sampling. The indirect effect of family stress on LS through anxiety symptoms was significant $(S E=0.01,95 \%=[-0.03,-0.02])$. The $95 \%$ biased-corrected confidence interval did not contain zero, which confirmed that anxiety symptoms played a mediating role on the association between family stress and LS.

Table 3 Mediated regression analysis for family stress and anxiety symptoms on LS 


\begin{tabular}{|llllll|}
\hline Variables & $B$ & $S E$ & $\beta$ & $t$ & $F$ \\
\hline Step 1. & & & & & \\
\hline Independent: Family stress & -1.13 & 0.02 & -0.51 & $-59.25^{\star \star \star}$ & $1801.09^{\star \star \star}$ \\
\hline Dependent: LS & & & & & \\
\hline Step 2. & & & & & \\
\hline Independent: Family stress & 0.74 & 0.01 & 0.52 & $60.49^{\star \star \star}$ & $1831.29^{\star \star \star}$ \\
\hline Dependent: Anxiety symptoms & & & & & \\
\hline Step 3. & & & & & \\
\hline Independent: Family stress & -0.95 & 0.02 & -0.43 & $-43.39^{\star \star \star}$ & $1310.60^{\star \star \star}$ \\
\hline Mediator: Anxiety symptoms & -0.24 & 0.02 & -0.15 & $-15.61^{\star \star \star}$ & \\
\hline Dependent: LS & & & & & \\
\hline
\end{tabular}

Note: ${ }^{\star} P<0.05 \rrbracket^{* \star} P<0.01{ }^{\star \star \star} P<0.001$

\section{Testing for the Moderated Mediation Model}

The results of the moderated mediation analyses for family stress, anxiety symptoms, age and LS were showed in Table 4. The PROCESS macro (Model 59) was used to test the moderated mediation, as is recommended by Bolin[39]. In Model 1, family stress was negatively related to $\operatorname{LS}(\beta=-0.51, p<0.001)$, and the interaction term between family stress and age was negatively related to $\operatorname{LS}(\beta=-0.03, p<0.01)$, which indicated that the age could moderated the association between family stress and LS. Model 2 was significant, family stress was positively related to anxiety symptoms $(\beta=0.51, p<0.001)$, and the interaction term between family stress and age was not related to anxiety symptoms, which indicated that the relationship between family stress and anxiety symptoms could not be moderated by age. Model 3 was also significant, anxiety symptoms was negatively related to LS $(\beta=-0.15, p<0.001)$, and the interaction term between anxiety symptoms and age was positively related to $\operatorname{LS}(\beta=0.03, p<0.1)$, which demonstrated that the age moderated the association between anxiety symptoms and LS.

These results indicated that the relationships between both family stress and LS as well anxiety symptoms and family stress are moderated by age. To more thoroughly understand the moderating effect of age, the present study plotted the association between family and LS, separately for younger and middle-aged groups. Simple slope test presented the association between family stress and LS (Fig 1). For women from younger group, the family stress was significantly and negatively associated with LS $(\beta=-0.39, t=-28.00, p<0.001)$. For women from middle-aged group, family stress was also negatively 
related to LS but considerably weaker $(\beta=-0.47, t=-33.36, p<0.001)$. And Fig 2 showed the simple slope test results of the association between anxiety symptoms and LS scores. As for women from young group, anxiety symptoms was significantly and negatively associated with $\mathrm{LS}(\beta=-0.18, t=-12.70, p$ $<0.001$ ), and for middle-aged women, resilience was still negatively correlated with LS, but much strengthener $(\beta=-0.13, t=-9.40, p<0.001)$.

The index of the moderated mediation was $0.01, S E=0.006$, and the biased-corrected $95 \%$ confidence interval for index of moderated mediation was from 0.002 to 0.025 , which did not contain zero. For younger workers, family stress negatively predicted LS (effect $=-0.09, t=0.008,95 \% \mathrm{Cl}[-0.108,-0.077]$ ), while among those with higher age, family stress had a significant but weaker prediction on LS (effect $=-0.07, \mathrm{t}=0.008,95 \% \mathrm{Cl}[-0.082,-0.050]$ ).

Table 4 Moderated mediation effect of anxiety symptoms on LS

\begin{tabular}{|c|c|c|c|c|c|c|}
\hline \multirow[t]{2}{*}{ Variables } & \multicolumn{2}{|c|}{$\begin{array}{l}\text { Model } 1 \\
\text { (Life satisfaction) }\end{array}$} & \multicolumn{2}{|c|}{$\begin{array}{l}\text { Model } 2 \\
\text { (Anxiety symptoms) }\end{array}$} & \multicolumn{2}{|c|}{$\begin{array}{l}\text { Model } 3 \\
\text { (Life satisfaction) }\end{array}$} \\
\hline & $\beta$ & $t$ & $\beta$ & $t$ & $\beta$ & $t$ \\
\hline Family stress & -0.51 & 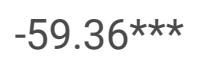 & 0.51 & $60.31 * \star *$ & -0.43 & $-43.45^{\star \star \star}$ \\
\hline Age & 0.10 & $11.64^{\star \star \star}$ & -0.04 & $-4.88^{\star \star \star}$ & 0.09 & $10.81^{\star \star \star}$ \\
\hline Family stress $\times$ Age & -0.03 & $-3.19 * \star$ & -0.01 & -1.53 & -0.04 & 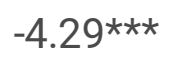 \\
\hline Anxiety symptoms & & & & & -0.15 & $-15.74 * \star \star$ \\
\hline $\begin{array}{l}\text { Anxiety symptoms } \times \\
\text { Age }\end{array}$ & & & & & 0.03 & $2.55^{\star}$ \\
\hline$R^{2}$ & 0.26 & & 0.26 & & 0.28 & \\
\hline$F$ & 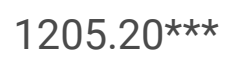 & & 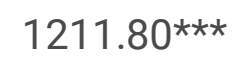 & & $791.34^{\star * *}$ & \\
\hline
\end{tabular}

Note: ${ }^{*} P<0.05 \rrbracket{ }^{* \star} P<0.01 \rrbracket^{\star \star \star} P<0.001$

\section{Discussions}

This study explored the relationship among age, family stress, anxiety symptoms and LS in female workers in China. To our knowledge, this study is the first to report the levels of LS among female workers after resuming to work during the COVID-19 epidemic, and to explore underlying mediating and moderating mechanisms among these associations. The research results revealed the average score on LS of female workers is $20.75 \pm 7.08$, which is lower than the score of Chinese participants in China $(22.92 \pm 6.46)$ and women in Brazil $(24.53 \pm 4.96)$ before the outbreak of the epidemic, and it is also lower 
than the score of Brazil participants $(21.88 \pm 6.87$ ) on March, 2020 (a period corresponding to 10 days in the pandemic) [41-43]. The above of difference may, to a great extent, result from the impact of the epidemic, but also may be affected by culture, languages and research methods used [31].According to the results, age, educational degree and annual income were positively related to LS. The LS scores were also influenced by occupation, marital status and the pregnancy and fertility. Hence, it emphasized the relevant community, organization, and business should take interventions considering these aspects to help their members to cope with declined LS during this special period.

In this study, family stress is negatively related to LS, which is consistent with previous studies[44-46]. And in line with our hypothesis, anxiety symptoms mediated the relationship between family stress and LS. Those participants who perceive higher stress attribute to the Public health event express higher mental distress, which has been demonstrated in other study [47]. According to the Eysenck's theories of anxiety[48], the long-term memory of people with different levels of trait anxiety is different, it explains why someone have anxiety symptoms but others do not when in times of stress. System tension theory also points out that after an emergency event, system tension will increase. The mental health status will decrease and the risk of negative coping behavior will be greatly increase with the higher level of tension [49]. And the research carried out among communities during the COVID-19 epidemic in China also indicated that residents who have high level of anxiety symptoms usually take negative behaviors such as drinking and smoking, which greatly affect LS[50]. Severe anxiety symptoms can greatly impact quality of life, cause learning disabilities and make people more vulnerable to diseases, and eventually lead to low LS. Meanwhile, positive mental health status is related to ideal work results, which can increase LS[51].

In summary, higher family stress level not only directly affects LS, but also further reduces LS via increasing the severity of anxiety symptoms. Additionally, these findings emphasized the need for focusing on the LS among female workers. And measures aiming at reducing perceived family stress and improving mental health should be applied to promote the levels of LS. From an intervention or prevention perspective, the psychotherapy methods such as cognitive behavioral therapy (CBT) can be used. Cognitive therapy should mainly focus on the excessive worries and overestimation of the consequences of COVID-19 epidemic among female workers. Behavioral therapy should encourage female workers to engage in more exercises such as running, doing yoga, swimming and other forms of exercises after getting off work to relieve their anxiety and stress. In addition, communicating frequently with your family about your worries and concerns is also important. At the same time, the government and health authorities should provide the latest and accurate information on the number of cases, locations, risk areas, and drugs or vaccines about the epidemic to reduce the psychological impact of rumors. And health authorities should urge female workers to wear masks at all times and actively take personal protective measures. And the company should also provide psychological counseling services and provide adequate personal hygiene products.

As we expected, age moderated the relationship between family stress and LS. The results showed that younger female workers tend to have lower LS. Age moderated the relationship between family stress and 
LS. This research stated that family stress has a stronger negative impact on middle-aged female workers than young female workers. Previous studies have shown that age is negatively correlated with mental flexibility. The psychological resilience of young female workers may be higher than that of middle-aged women. Higher psychological resilience not only relieve stress and maladaptation [44], but also has important significance for promoting the development of coping mechanisms [52]. The development of the mechanism has great significance. This showed that young women may have greater ability to cope with family stress. Under the same family stress, young women's LS is less likely to be affected compare to middle-aged women.

In addition, age moderated the relationship between anxiety symptoms and LS, and the negative impact of anxiety symptoms on young women is stronger than that of middle-aged women, which can be explained by the socioemotional selectivity theory; namely older adults keep away from negative emotion from themselves[53]. As they grow older, individuals may have more mature defense mechanisms. When facing negative emotions, they will adopt more reasonable and appropriate ways to deal with them, such as good emotional control and seeking help from others. When conflict occurs, older people tend to stay away from it, or give it a positive and pleasant explanation[54]. As the result, middle-aged women can better deal with anxiety symptoms to reduce the impact on LS.

We have not found age moderated the relationship between family stress and anxiety symptoms. This finding may suggest that family stress has a negative impact on female workers' mental health status, but had nothing to do with age. And it will lead to negative emotions such as anxiety and depression. These findings are consistent with previous studies, confirming the positive correlation between perceived stress and individual anxiety symptoms $[55,56]$.

\section{Limitations}

Several limitations in this study must be noted. Firstly, the current study was a cross-sectional design which limited the ability to draw causal conclusions in terms of the relationship analyzed. Therefore, the results of this study should be confirmed by further longitudinal studies. Secondly, all data were collected through self-reported questionnaires. Shared-rater bias may have affected associations between family stress and LS among female workers, which undermined the generalization of results. The participants were limited to female workers in a certain region of Northeast China. So be cautious when extending the results to women in other regions or other groups. Finally, LS is a complex indicator, which may be affected by several factors. Family stress and anxiety symptoms could only explain a small part of it. We have not investigated other important factors concerning LS. Therefore, we should establish a more comprehensive model to study the influencing factors of LS in the future.

\section{Conclusion}

This research has significant theoretical and practical implications. Through the exploration of the moderated mediation model, it revealed that higher family stress can lead to aggravation of anxiety 
symptoms, thereby reducing LS. We concluded from these findings that public health policies can support female workers in coping with the bad impacts of the COVID-19 epidemic by improving mental health status. In addition, interventions aimed to reduce family stress level should also be taking into consideration. Furthermore, age could moderate the impact of family stress on LS. With the increase of age, the association between family stress and LS has been weakened significantly. Hence, the young women groups should be given special priority when emergency occurs. This study provided a reference for formulating intervention measures in the short and long term of the COVID-19 epidemic or similar events in the future.

\section{Abbreviations}

COVID-19: Coronavirus Disease 2019; LS: Life satisfaction; Cl: Confidence interval; OR: Odds ratio; SD: Standard deviation; SE: Standard error

\section{Declarations}

\section{Acknowledgments}

The authors would like to thank the strong support from Female Workers' Committee of Jilin Federation of Trade Unions, and research group members for contribution to data collection and for their selfless support of the study.

\section{Authors' contributions}

SM and TY conceptualized and designed the study. YCH, RC and CL carried out the data collection. SM, TY and LL performed data analysis and writing original draft. ZQ, HR, YYH and JF reviewed and edited the manuscript. All authors have read and approved the final version.

\section{Funding}

This research was funded by International innovation team of Jilin University (2019GJTD06).

\section{Availability of data and materials}

The datasets used or analyzed during the current study are available from the corresponding author upon reasonable request.

\section{Ethics approval and consent to participate}

The study was approved by the Institutional Review Board of the School of Public Health, Jilin University. The research was conducted in accordance with the Helsinki Declaration as revised 1989. All participants had given their online informed consent to participate in the study, and they were totally voluntary and 
anonymous. We protected the privacy of participants in processing personal data and maintained confidentiality of individual records and accounts.

\section{Consent for publication}

Not applicable.

\section{Competing interests}

The authors declare that they have no competing interests.

\section{Author details}

${ }^{1}$ School of Public Health, Jilin University, Changchun 130021, China. ${ }^{2}$ Department of Gastrointestinal Colorectal and Anal Surgery, the first Hospital of Jilin University, Changchun, China.

\section{References}

1. Hui DS, Madani EIA, Ntoumi TA, Kock F, Dar R, Ippolito O, McHugh G, Memish TD, Drosten ZA. C et al: The continuing 2019-nCoV epidemic threat of novel coronaviruses to global health - The latest 2019 novel coronavirus outbreak in Wuhan, China. International journal of infectious diseases: IJID : official publication of the International Society for Infectious Diseases 2020, 91:264-6.

2. Liang L, Ren H, Cao R, Hu Y, Qin Z, Li C, Mei S. The Effect of COVID-19 on Youth Mental Health. Psychiatr Q. 2020;91(3):841-52.

3. Bohlken J, Schömig F, Lemke MR, Pumberger M, Riedel-Heller SG. [COVID-19 Pandemic: Stress Experience of Healthcare Workers - A Short Current Review]. Psychiatr Prax. 2020;47(4):190-7.

4. Pedrozo-Pupo JC, Pedrozo-Cortés MJ, Campo-Arias A. Perceived stress associated with COVID-19 epidemic in Colombia: an online survey. Cadernos de saude publica 2020, 36(5).

5. Maunder RG, Lancee WJ, Balderson KE, Bennett JP, Borgundvaag B, Evans S, Fernandes CMB, Goldbloom DS, Gupta M, Hunter JJ, et al. Long-term psychological and occupational effects of providing hospital healthcare during SARS outbreak. Emerg Infect Dis. 2006;12(12):1924-32.

6. Qiu J, Shen B, Zhao M, Wang Z, Xie B, Xu Y. A nationwide survey of psychological distress among Chinese people in the COVID-19 epidemic: implications and policy recommendations. General psychiatry 2020, 33(2).

7. Wang C, Pan R, Wan X, Tan Y, Xu L, Ho CS, Ho RC. Immediate Psychological Responses and Associated Factors during the Initial Stage of the 2019 Coronavirus Disease (COVID-19) Epidemic among the General Population in China. International Journal of Environmental Research and Public Health 2020, 17(5).

8. Hall RCW, Hall RCW, Chapman MJ. The 1995 Kikwit Ebola outbreak: lessons hospitals and physicians can apply to future viral epidemics. Gen Hosp Psychiatry. 2008;30(5):446-52. 
9. Delongis A, Folkman S, Lazarus RS. THE IMPACT OF DAILY STRESS ON HEALTH AND MOOD PSYCHOLOGICAL AND SOCIAL RESOURCES AS MEDIATORS. J Personal Soc Psychol 1988, 54(3):486-95.

10. Karatzias T, Chouliara Z, Power K, Brown K, Begum M, McGoldrick T, MacLean R. Life satisfaction in people with post-traumatic stress disorder. J Ment Health. 2013;22(6):501-8.

11. Liang L, Gao T, Ren H, Cao R, Qin Z, Hu Y, Li C, Mei S. Post-traumatic stress disorder and psychological distress in Chinese youths following the COVID-19 emergency. Journal of health psychology 2020, 25(9):1164-75.

12. Stansfeld SA, Fuhrer R, Head J. Impact of common mental disorders on sickness absence in an occupational cohort study. Occupational and environmental medicine 2011, 68(6):408-13.

13. Diener E, Emmons RA, Larsen RJ, Griffın S. The Satisfaction With Life Scale. J Pers Assess. 1985;49(1):71-5.

14. Poorbaferani Z, Mazaheri MA, Hasanzadeh A. Life satisfaction, general self-efficacy, self-esteem, and communication skills in married women. Journal of education and health promotion 2018, 7:173.

15. Park SM, Kim HC, Park SG, Jang HS, Choi G, Leem JH. Satisfaction with life and the risk of occupational injury. Annals of occupational and environmental medicine 2018, 30:49.

16. Cao Q, Liang Y. Perceived social support and life satisfaction in drug addicts: Self-esteem and Ioneliness as mediators. Journal of health psychology 2020, 25(7):976-85.

17. Ko CH, Yen CF, Yen JY, Yang MJ. Psychosocial impact among the public of the severe acute respiratory syndrome epidemic in Taiwan. Psychiatry and clinical neurosciences 2006, 60(4):397403.

18. Peng EY, Lee MB, Tsai ST, Yang CC, Morisky DE, Tsai LT, Weng YL, Lyu SY. Population-based postcrisis psychological distress: an example from the SARS outbreak in Taiwan. Journal of the Formosan Medical Association = Taiwan yi zhi. 2010;109(7):524-32.

19. Yeung NCY, Lau JTF, Choi KC, Griffiths S. Population Responses during the Pandemic Phase of the Influenza A(H1N1)pdm09 Epidemic, Hong Kong, China. Emerging infectious diseases 2017, 23(5):813-5.

20. Shultz JM, Baingana F, Neria Y. The 2014 Ebola outbreak and mental health: current status and recommended response. Jama 2015, 313(6):567-8.

21. Cardwell MS. Stress: pregnancy considerations. Obstet Gynecol Surv. 2013;68(2):119-29.

22. Glover V. Maternal depression, anxiety and stress during pregnancy and child outcome; what needs to be done. Best practice research Clinical obstetrics gynaecology. 2014;28(1):25-35.

23. Daig I, Herschbach P, Lehmann A, Knoll N, Decker O. Gender and age differences in domain-specific life satisfaction and the impact of depressive and anxiety symptoms: a general population survey from Germany. Quality of life research: an international journal of quality of life aspects of treatment care rehabilitation. 2009;18(6):669-78. 
24. Oosterveer DM, Mishre RR, van Oort A, Bodde K, Aerden LA. Anxiety and low life satisfaction associate with high caregiver strain early after stroke. J Rehabil Med. 2014;46(2):139-43.

25. Yazdanshenas Ghazwin M, Kavian M, Ahmadloo M, Jarchi A, Golchin Javadi S, Latifi S, Tavakoli SA, Ghajarzadeh M. The Association between Life Satisfaction and the Extent of Depression, Anxiety and Stress among Iranian Nurses: A Multicenter Survey. Iranian journal of psychiatry. 2016;11(2):120-7.

26. Yu M, Qiu T, Liu C, Cui Q, Wu H. The mediating role of perceived social support between anxiety symptoms and life satisfaction in pregnant women: a cross-sectional study. Health and quality of life outcomes 2020, 18(1):223.

27. Cohen Jl. Stress and mental health: a biobehavioral perspective. Issues in mental health nursing 2000, 21(2):185-202.

28. Currier D, Spittal MJ, Patton G, Pirkis J. Life stress and suicidal ideation in Australian men - crosssectional analysis of the Australian longitudinal study on male health baseline data. BMC Public Health. 2016;16(Suppl 3):1031.

29. Fan LB, Blumenthal JA, Watkins LL, Sherwood A. Work and home stress: associations with anxiety and depression symptoms. Occupational medicine (Oxford, England) 2015, 65(2):110-6.

30. van der Waerden JE, Hoefnagels C, Hosman CM, Jansen MW. Defining subgroups of low socioeconomic status women at risk for depressive symptoms: the importance of perceived stress and cumulative risks. The International journal of social psychiatry 2014, 60(8):772-82.

31. Huang H, Liu S, Sharma A, Zou F, Tian F, Wu H. Factors associated with life satisfaction among married women in rural China: a cross-sectional study based on large-scale samples. Psychology research behavior management. 2018;11:525-33.

32. Brown RL, Richman JA, Rospenda KM. Economic Stressors and Psychological Distress: Exploring Age Cohort Variation in the Wake of the Great Recession. Stress and health: journal of the International Society for the Investigation of Stress 2017, 33(3):267-77.

33. Etxeberria I, Urdaneta E, Galdona N. Factors associated with health-related quality of life (HRQoL): differential patterns depending on age. Quality of life research: an international journal of quality of life aspects of treatment care rehabilitation. 2019;28(8):2221-31.

34. Vassar M. A note on the score reliability for the Satisfaction With Life Scale: an RG study. Soc Indic Res. 2008;86(1):47-57.

35. Loerbroks A, Ding H, Han W, Wang H, Wu JP, Yang L, Angerer P, Li J. Work stress, family stress and asthma: a cross-sectional study among women in China. International archives of occupational and environmental health 2017, 90(4):349-56.

36. Zhou M, Wege N, Gu H, Shang L, Li J, Siegrist J. Work and family stress is associated with menstrual disorders but not with fibrocystic changes: cross-sectional findings in Chinese working women. Journal of occupational health 2010, 52(6):361-6.

37. Löwe B, Decker O, Müller S, Brähler E, Schellberg D, Herzog W, Herzberg PY. Validation and standardization of the Generalized Anxiety Disorder Screener (GAD-7) in the general population. 
Medical care. 2008;46(3):266-74.

38. Sapra A, Bhandari P, Sharma S, Chanpura T, Lopp L: Using Generalized Anxiety Disorder-2 (GAD-2) and GAD-7 in a Primary Care Setting. Cureus 2020, 12(5).

39. Bolin JH. Introduction to Mediation, Moderation, and Conditional Process Analysis: A RegressionBased Approach. J Educ Meas. 2014;51(3):335-7.

40. Baron RM, Kenny DA. The moderator-mediator variable distinction in social psychological research: conceptual, strategic, and statistical considerations. J Personal Soc Psychol. 1986;51(6):1173-82.

41. Gori A, Topino E, Di Fabio A. The protective role of life satisfaction, coping strategies and defense mechanisms on perceived stress due to COVID-19 emergency: A chained mediation model. PloS one 2020, 15(11).

42. Gouveia VV, Milfont TL, da Fonseca PN, Pecanha de Miranda Coelho JA. Life Satisfaction in Brazil: Testing the Psychometric Properties of the Satisfaction With Life Scale (SWLS) in Five Brazilian Samples. Soc Indic Res. 2009;90(2):267-77.

43. Liu T, Zeng X, Chen M, Lan T. The Harder You Work, the Higher Your Satisfaction With Life? The Influence of Police Work Engagement on Life Satisfaction: A Moderated Mediation Model. Frontiers in psychology. 2019;10:826.

44. Shi M, Wang X, Bian Y, Wang L. The mediating role of resilience in the relationship between stress and life satisfaction among Chinese medical students: a cross-sectional study. BMC medical education. 2015;15:16.

45. Smyth JM, Zawadzki MJ, Juth V, Sciamanna CN. Global life satisfaction predicts ambulatory affect, stress, and cortisol in daily life in working adults. Journal of behavioral medicine 2017, 40(2):32031.

46. Zhou S, Da S, Guo H, Zhang X. Work-Family Conflict and Mental Health Among Female Employees: A Sequential Mediation Model via Negative Affect and Perceived Stress. Frontiers in psychology 2018, 9:544.

47. Wang CY, Pan RY, Wan XY, Tan YL, Xu LK, Ho CS, Ho RC. Immediate Psychological Responses and Associated Factors during the Initial Stage of the 2019 Coronavirus Disease (COVID-19) Epidemic among the General Population in China. International Journal of Environmental Research and Public Health 2020, 17(5).

48. Hamilton V: THEORIES OF ANXIETY AND HYSTERIA -. A REJOINDER TO EYSENCK,HANS. British Journal of Psychology 1959, 50(3):276-80.

49. Cheng C, Cheung MW. Psychological responses to outbreak of severe acute respiratory syndrome: a prospective, multiple time-point study. Journal of personality. 2005;73(1):261-85.

50. Sun Y, Li Y, Bao Y, Meng S, Sun Y, Schumann G, Kosten T, Strang J, Lu L, Shi J. Brief Report: Increased Addictive Internet and Substance Use Behavior During the COVID-19 Pandemic in China. The American journal on addictions. 2020;29(4):268-70.

51. Dyrbye LN, Harper W, Moutier C, Durning SJ, Power DV, Massie FS, Eacker A, Thomas MR, Satele D, Sloan JA, et al. A multi-institutional study exploring the impact of positive mental health on medical 
students' professionalism in an era of high burnout. Academic medicine: journal of the Association of American Medical Colleges. 2012;87(8):1024-31.

52. Wu G, Feder A, Cohen H, Kim JJ, Calderon S, Charney DS, Mathé AA. Understanding resilience. Front Behav Neurosci. 2013;7:10.

53. Sullivan-Singh SJ, Stanton AL, Low CA. Living with limited time: Socioemotional selectivity theory in the context of health adversity. Journal of personality and social psychology 2015, 108(6):900-16.

54. Mirowsky J, Ross CE. Age and the effect of economic hardship on depression. Journal of health social behavior. 2001;42(2):132-50.

55. Herbison CE, Allen K, Robinson M, Newnham J, Pennell C. The impact of life stress on adult depression and anxiety is dependent on gender and timing of exposure. Dev Psychopathol. 2017;29(4):1443-54.

56. Luo Y, Meng R, Li J, Liu B, Cao X, Ge W. Self-compassion may reduce anxiety and depression in nursing students: a pathway through perceived stress. Public Health. 2019;174:1-10.

\section{Figures}

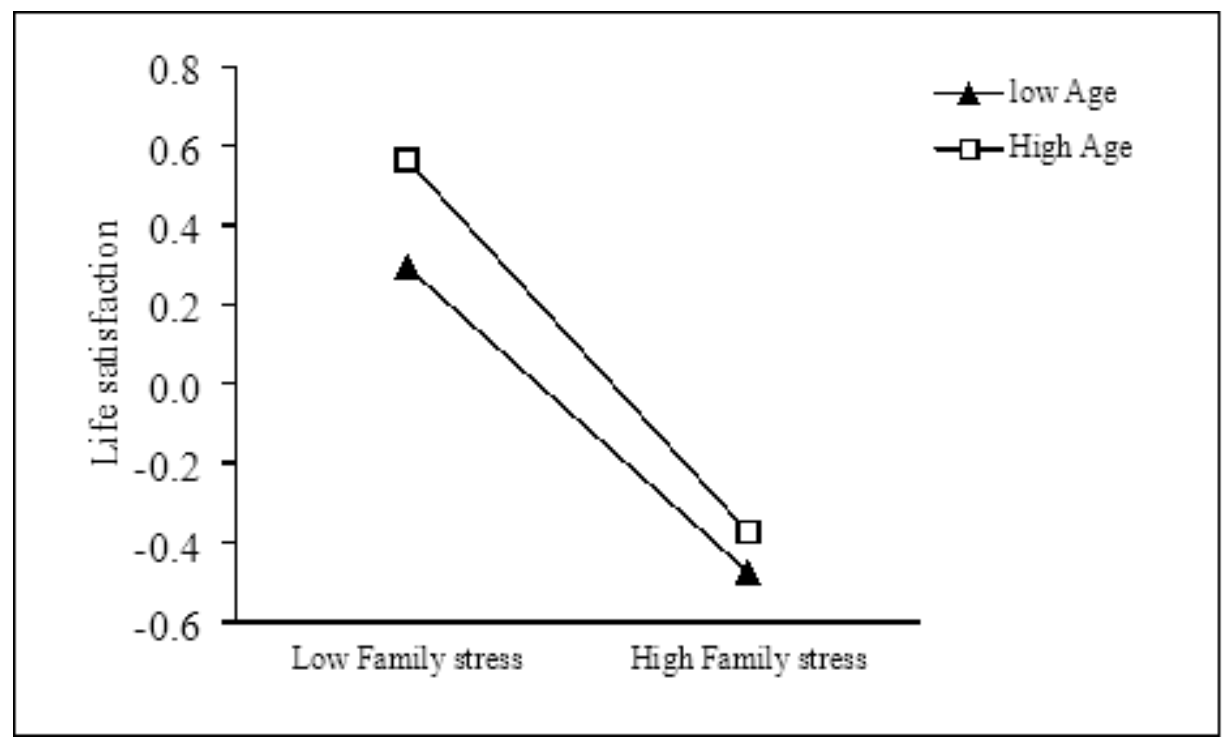

\section{Figure 1}

Age moderate the relationship between family stress and LS. 


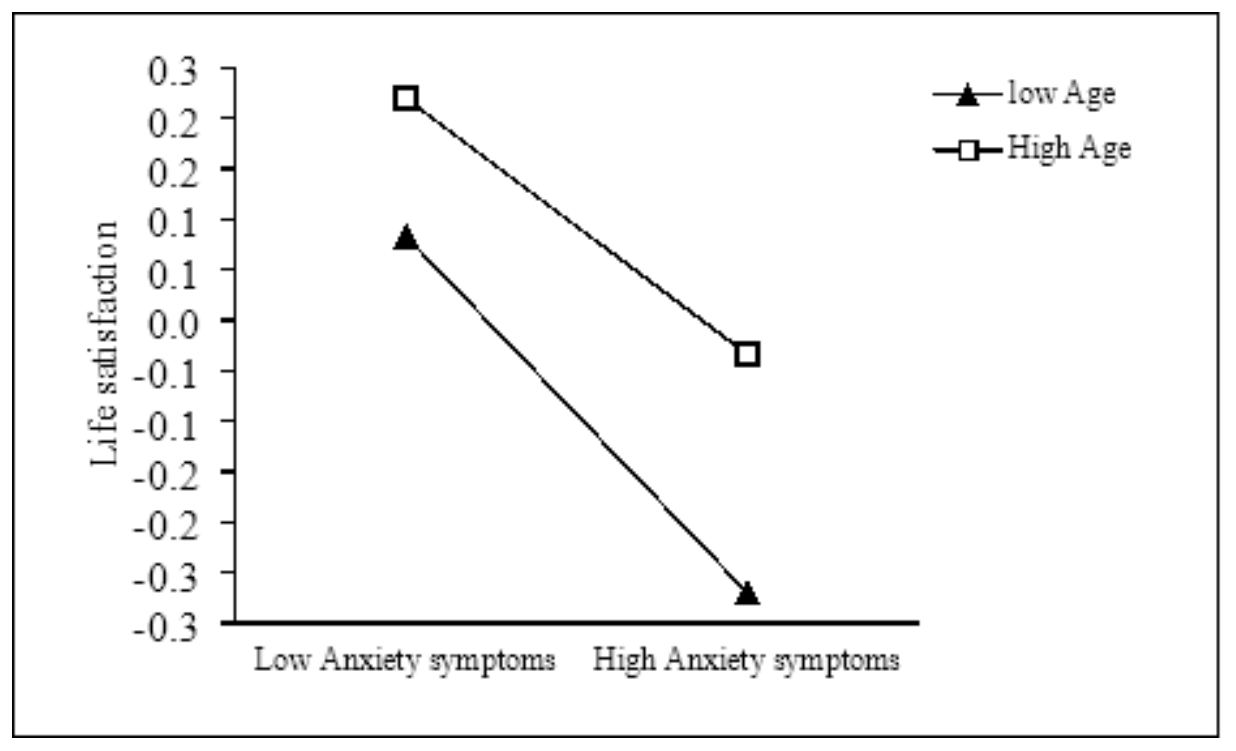

Figure 2

Age moderate the relationship between Anxiety symptoms and LS. 